\title{
GLOBAL HEALTH PROFESSIONS STUDENT SURVEY- TURKEY: SECOND-HAND SMOKE EXPOSURE AND OPINIONS OF MEDICAL STUDENTS ON ANTI-TOBACCO LAW
}

\author{
Tacettin Inandi', Ozge Karadag Caman², Neriman Aydın², Ayşe Emel Onal ${ }^{4}$, Ayşe Kaypmaz ${ }^{5}$, Ebru Turhan ${ }^{6}$, Toker \\ Erguder $^{7}$, Wick C. Warren ${ }^{8}$ \\ ${ }^{1}$ Department of Public Health, Medical Faculty, Mustafa Kemal University, Hatay, Turkey \\ ${ }^{2}$ Department of Public Health, Medical Faculty, Hacettepe University, Ankara, Turkey \\ ${ }^{3}$ Department of Public Health, Medical Faculty, Gaziantep University, Gaziantep, Turkey \\ ${ }^{4}$ Department of Public Health, Istanbul Medical Faculty, Istanbul University, Istanbul, Turkey \\ ${ }^{5}$ Department of Public Health, Cerrahpasa Medical Faculty, Istanbul University, Istanbul, Turkey \\ ${ }^{6}$ Department of Public Health, Medical Faculty, Mustafa Kemal University, Hatay, Turkey \\ ${ }^{7}$ National Tobacco Control Programme Officer, Bloomberg Initiative, WHO Country Office, Ankara, Turkey \\ ${ }^{8}$ Centers for Disease Control and Prevention, Atlanta, Georgia, USA
}

\section{SUMMARY}

Aim: This study, as a part of " the Global Health Professions Student Survey" (GHPSS), aimed to assess medical students' tobacco use, exposure to second-hand tobacco smoke (SHS), and opinions as well as smoking policies at medical faculties in Turkey.

Methods: The study was conducted in 2010 as a school-based survey of third-year students in 12 medical schools. GHPSS uses a standardised methodology for selecting schools (probability proportional to student enrolment size) and data processing. In total, data from 1,217 of third year medical students were analysed.

Results: Prevalence of current tobacco use among participating students was $28.5 \%$. Exposure to SHS in the last seven days was $46.9 \%$ at home, and $42.2 \%$ in other places. Among smokers, over 7 in 10 students reported smoking on medical school premises during the past 30 days and the past year.

Conclusion: Medical students' exposure to SHS is common and smoking on medical school premises/buildings constitutes a problem. Turkey passed an anti-tobacco law in 2008, yet enforcement of the law must be stronger. In addition, medical schools must evaluate, and likely revise their education curricula to better prepare medical students to advocate tobacco control.

Key words: second-hand smoke, tobacco, legislation, medical students, medical schools

Address for correspondence: O. K. Caman, Hacettepe Universitesi Tip Fakultesi Halk Sağlığı Anabilim Dalı, 06100 Sihhiye Ankara, Turkey. E-mail: ozgecaman@hacettepe.edu.tr

\section{INTRODUCTION}

Tobacco use is one of the most important public health problems in the world. In 2008, tobacco killed more than five million people. It is estimated that unless urgent and efficient measures are taken, tobacco use could kill one billion people during the 21 st century (1).

Second-hand tobacco smoke (SHS) or passive smoke is the combination of side stream smoke, i.e. smoke that is emitted between puffs of burning tobacco and mainstream smoke, i.e. smoke that is exhaled by the smoker (2). SHS has been designated as a known human carcinogen by the International Agency for Research on Cancer (3). Health effects associated with exposure to SHS have been well documented and include lung cancer, lower respiratory tract infections, asthma, cardiovascular disease, eye and nasal irritation, and low birth weight in babies of non-smokers (2). Oberg et al. in their retrospective analysis of data from 192 countries reported that worldwide $40 \%$ of children, $33 \%$ of male non-smokers and $35 \%$ of female non-smokers were exposed to SHS in 2004. In the same year, 603,000 deaths were attributable to SHS, which was about $1.0 \%$ of worldwide mortality. Disabilityadjusted life years lost due to SHS exposure amounted to 10.9 million, which was about $0.7 \%$ of the total worldwide burden of diseases in 2004 (4).

Scientific evidence has firmly established that there is no safe level of exposure to SHS, a pollutant that causes serious illnesses both in adults and children. Therefore, the elimination of smoking from indoor environments is the only science-based measure that adequately protects populations' health from the dangerous effects of SHS (5). Thus, full enforcement of smoke-free laws is critical for establishing their credibility, especially immediately following their enactment (1).

Today, many countries in the world have enacted tobacco control legislation. In Brazil, strong legislation and a coordinated 
approach to national, state and local activity have made the country a global leader. Canada has persistently overcome obstacles to set global standards for best practices in warning labels and other areas. In Norway, a ground breaking 1973 law provided a flexible framework for comprehensive legislation that still sets global standards (6). Legislative initiatives in the European Union to curb tobacco use among citizens have been on the agenda since the 1980's (7).

Meanwhile, Turkey has experienced great achievements in tobacco control, particularly in the area of smoke-free environments. The first legislation came into force in 1996, which banned smoking in most enclosed places. After more than 10 years of implementation, the law was amended in 2008, covering all public (state) buildings, health care facilities, public transportation, and hospitality workplaces (restaurants and coffee houses). Despite these achievements, data on implementation and enforcement of the law at the national and local level are scarce, and need to be assessed.

Medical students, as future physicians, constitute one of the key groups to study with regards to their smoking habits, exposure to SHS at home and school environments, and their opinions on tobacco control. Assessment of existing smoking policies and practices of medical schools is also crucial with regards to tobacco control.

This study, as a part of international study called "the Global Health Profession Student Survey" (GHPSS), aimed to assess self-reported tobacco use and exposure to SHS among third year medical students as well as the students' opinions and official policies and practices of the medical faculties concerning the 2008 anti-tobacco law in Turkey.

\section{MATERIALS AND METHODS}

GHPSS has a standardized methodology for selecting participating schools and classes and uniform data processing procedures. It is a school-based survey of third-year students in dentistry, medicine, nursing and/or pharmacy.

\section{Study Sample}

In 2008, there were 66 medical faculties in Turkey (8). Of them, 51 medical schools had 3rd year students in the academic year of 2006-2007. The total enrolment size of those 51 schools was 4,980. The Turkey GHPSS used a two-stage sample design: In Stage 1, 12 schools were selected using probability proportion to student enrolment size (PPS) procedures. Stage 2 consisted of selecting all classes teaching 3rd year students in each of the 12 selected schools. All 3rd year medical students in the schools were eligible for participation in the survey.

\section{Response Rate}

Data of this study were collected in December 2009 and January 2010. All students in selected classes who attended school on the day of the survey were eligible to participate. The school participation rate was $100.0 \%$, and $1,889(86.4 \%)$ of the 2,186 eligible students completed the survey. The overall response rate was $86.4 \%$. Of the 1,889 students who participated in GHPSS, 1,217 were 3 rd year students, and 672 were in other years. Only data obtained from the 3 rd year students were included in this paper.

\section{Study Questionnaire}

GHPSS is composed of a core questionnaire designed to gather data on five topics related to the prevalence of tobacco use, exposure to SHS, training and knowledge about the health effects of tobacco use, attitudes towards tobacco use, and cessation of tobacco use. This paper focuses on SHS.

The core questionnaire was translated into Turkish and backtranslated into English to check for accuracy. Furthermore, a focus group of 3rd year medical students (enrolled in schools other than the selected 12 schools) was conducted to test the accuracy of the translation and comprehension of the questions.

\section{Data Collection Procedures}

An invitation letter was sent to the deans of the selected schools. Survey administrators were recruited from public health departments of each selected school for data collection. Survey procedures were designed to protect the students' privacy by allowing for anonymous and voluntary participation. The self-administered questionnaire was administered in the classrooms.

\section{Data Analysis}

All analysis used weighted data (weighted for the probability of selection of the school and non-response at the school and student levels). Statistical differences were determined by comparing $95 \%$ Confidence Intervals (CI). If CIs did not overlap, then differences were significant at the $\mathrm{p}<0.5$ level.

\section{Definitions}

In this study, "Ever user" was defined as "having used tobacco at least once in a lifetime'. "Current user" was defined as 'having used tobacco at least once in the last 30 days preceding the survey'. "Never user" was defined as 'having not used tobacco even once in a lifetime'.

\section{RESULTS}

In this study, the total number of 3rd year medical students who were included in the analysis was 1,217 . Of the participants, $55.3 \%(n=632)$ were female and $44.7 \%(n=578)$ were male. The majority $(96.7 \%)$ of students were in the 19-24 age group.

\section{Tobacco Use}

In terms of tobacco use, $68.0 \%$ of the medical students reported to use any tobacco product (cigarette, water-pipe etc.) at least once in their lifetime and $28.5 \%$ reported to be current tobacco users.

Almost 1 out of 5 students (19.3\%) reported they were current cigarette smokers. Male students $(29.3 \%)$ were more likely than female students $(11.1 \%)$ to be current smokers and the difference with respect to gender was statistically significant $(p<0.05)$. Male students were almost twice as likely as female students to use tobacco products other than cigarettes $(23.8 \%$ vs. $12.9 \%)$ and to have smoked any tobacco product ( $40.2 \%$ vs. $18.9 \%)$ (Table 1$)$. 
Table 1. Prevalence of smoking among medical students, GHPSS-2010, Turkey

\begin{tabular}{|l|c|c|c|c|c|c|c|}
\hline \multirow{2}{*}{} & \multicolumn{4}{|c|}{ Prevalence of smoking } & \multicolumn{3}{c|}{ Total } \\
\cline { 2 - 9 } & \multicolumn{2}{|c|}{ Male } & \multicolumn{2}{c|}{ Female } & \multicolumn{3}{c|}{} \\
\hline Smoking status & $\%$ & $95 \% \mathrm{Cl}$ & $\%$ & $95 \% \mathrm{Cl}$ & $\%$ & $95 \% \mathrm{Cl}$ & $\mathrm{n}^{*}$ \\
\hline Current cigarette smokers & 29.3 & $22.6-37.0$ & 11.1 & $8.4-14.5$ & 19.3 & $15.2-24.1$ & 1197 \\
\hline Current other product users & 23.8 & $18.3-30.3$ & 12.9 & $7.7-21.0$ & 17.9 & $13.9-22.8$ & 1216 \\
\hline Any tobacco product users & 40.2 & $30.9-50.3$ & 18.9 & $13.2-26.4$ & 28.5 & $22.7-35.2$ & 1217 \\
\hline
\end{tabular}

${ }^{*} \mathrm{n}$ is the total number of responses. Differences in the numbers are caused by the missing responses.

\section{Exposure to SHS}

Almost half (46.9\%) of the students reported that they had been exposed to SHS at their home in the past seven days; there was no significant difference in exposure among male and female students (Table 2). Over 3 in 10 never smokers (36.4\%) had been exposed to SHS at home compared to almost 7 in 10 current smokers $(69.6 \%)$ and the difference was statistically significant $(\mathrm{p}<0.05)$.

Over 4 in 10 students (42.2\%) reported they had been exposed to SHS at places other than their home in the past seven days; there was no significant difference in exposure among male and female students (Table 2). Almost 4 in 10 never smokers (37.4\%) and almost 6 in 10 current smokers (59.2\%) were exposed to SHS in places other than their home and the difference was statistically significant $(\mathrm{p}<0.05)$.

\section{Students' Opinions Regarding SHS}

Of the medical students surveyed, $90.7 \%$ thought that smoking should be banned in all enclosed public places. The level of support was significantly higher $(\mathrm{p}<0.05)$ among students who had never used tobacco $(97.3 \%)$ than in current users of it $(79.3 \%)$.

Smoking ban in restaurants was supported by $90.7 \%$ of all students. Similar to the above, the level of support was significantly higher $(\mathrm{p}<0.05)$ among students who had never used tobacco $(92.3 \%)$ than current users of tobacco $(78.3 \%)$. Answering the same question, $94.8 \%$ of female and $87.2 \%$ of male students thought smoking should be banned in restaurants; however the difference with respect to gender was insignificant $(\mathrm{p}>0.05)$ (Table 3).

Overall, $88.2 \%$ of the students stated that their school had an official policy banning smoking in school buildings and hospi- tal clinics. Furthermore, $87.2 \%$ of the students stated that their school's official smoking ban for school buildings and clinics was enforced.

Of those students who had ever smoked, almost 8 in $10(78.7 \%)$ reported that they smoked cigarettes on school premises/property during the past year. In addition, $73.0 \%$ reported that they had smoked cigarettes on school property in the past 30 days.

In contrast, only 2 in 10 students (22.1\%) who had ever smoked reported smoking in school buildings; and $12.2 \%$ had smoked in school buildings in the past 30 days (Table 4 ).

\section{DISCUSSION}

\section{Tobacco Use}

The GHPSS study for medical students in Turkey found that $68 \%$ of the students used any tobacco product at least once in their lifetime and $28.5 \%$ of them were current tobacco smokers; results are consistent with the findings of the 2008 Global Adult Tobacco Survey (GATS) - Turkey (9). GATS found that $31.2 \%$ of the adult population (persons above 15 years old) in Turkey were smokers.

Previous studies have shown that smoking prevalence among medical students increases with age $(10,11)$, which might indicate that current medical education does not decrease smoking rates among students. In the study of Onal et al., the percentage of smoking among 4th year medical students in Istanbul was $41 \%$ among male students and $21 \%$ among female students (12).

The consistent findings from GHPSS and GATS suggest that tobacco control efforts must include interventions reaching spe-

Table 2. Exposure to second-hand tobacco smoke among medical students, GHPSS-2010, Turkey

\begin{tabular}{|c|c|c|c|c|c|c|c|}
\hline \multirow[b]{3}{*}{ Exposure to SHS in past 7 days } & \multicolumn{4}{|c|}{ Exposure to second-hand tobacco smoke } & & & \\
\hline & \multicolumn{2}{|c|}{ Male } & \multicolumn{2}{|c|}{ Female } & \multicolumn{3}{|c|}{ Total } \\
\hline & $\%$ & $95 \% \mathrm{Cl}$ & $\%$ & $95 \% \mathrm{Cl}$ & $\%$ & $95 \% \mathrm{Cl}$ & $\mathrm{n}^{*}$ \\
\hline \multicolumn{8}{|l|}{ At home } \\
\hline Never cigarette smokers & 35.7 & $23.9-49.5$ & 36.8 & $29.3-44.9$ & 36.4 & $29.0-44.6$ & 517 \\
\hline Current cigarette smokers & 72.4 & $53.7-85.6$ & 64.2 & $41.9-81.6$ & 69.6 & $51.8-83.0$ & 230 \\
\hline All students & 52.7 & $44.6-60.6$ & 42.4 & $36.9-48.2$ & 46.9 & $40.0-54.0$ & 747 \\
\hline \multicolumn{8}{|l|}{ At places other than home } \\
\hline Never cigarette smokers & 43.8 & $34.1-54.1$ & 34.0 & $23.4-46.4$ & 37.4 & $27.9-47.9$ & 519 \\
\hline Current cigarette smokers & 62.3 & $49.2-73.8$ & 52.6 & $33.2-71.2$ & 59.2 & $48.0-69.5$ & 230 \\
\hline All students & 49.3 & $43.0-55.6$ & 36.3 & $25.7-48.5$ & 42.2 & $35.2-49.4$ & 749 \\
\hline
\end{tabular}

* $n$ is the total number of responses. Differences in the numbers are caused by the missing responses. 
Table 3. Opinions of the medical students on the ban of tobacco products in public places, GHPSS-2010, Turkey

\begin{tabular}{|c|c|c|c|}
\hline Questions & $\%$ of "Yes" responses & $95 \% \mathrm{Cl}$ & $\mathrm{n}^{*}$ \\
\hline \multicolumn{4}{|c|}{ Should smoking in all enclosed public places be banned? } \\
\hline Current cigarette smokers & 74.8 & $60.4-85.3$ & 226 \\
\hline Current any tobacco users & 79.3 & $68.4-87.2$ & 339 \\
\hline Never cigarette smokers & 96.4 & $94.8-97.5$ & 516 \\
\hline Never any tobacco users & 97.6 & $95.3-98.8$ & 374 \\
\hline \multicolumn{4}{|c|}{ Should smoking be banned in restaurants? } \\
\hline Males & 87.2 & $81.1-91.5$ & 573 \\
\hline Females & 94.8 & $91.4-96.9$ & 631 \\
\hline \multicolumn{4}{|c|}{ Should smoking be banned in restaurants? } \\
\hline Current cigarette smokers & 71.7 & $54.8-84.1$ & 231 \\
\hline Current any tobacco users & 78.3 & $64.7-87.7$ & 347 \\
\hline Never cigarette smokers & 97.4 & $95.2-98.6$ & 518 \\
\hline Never any tobacco users & 97.3 & $94.8-98.7$ & 375 \\
\hline
\end{tabular}

${ }^{*} \mathrm{n}$ is the total number of responses. Differences in the numbers are caused by the missing responses.

Table 4. Smoking on school premises and buildings among medical students, who have ever smoked, GHPSS-2010, Turkey

\begin{tabular}{|c|c|c|c|c|c|c|}
\hline \multirow[b]{2}{*}{ Questions } & \multicolumn{3}{|c|}{ During the past 30 days } & \multicolumn{3}{|c|}{ During the past year } \\
\hline & $\%$ & $95 \% \mathrm{Cl}$ & $\mathrm{n}^{*}$ & $\%$ & $95 \% \mathrm{Cl}$ & $\mathrm{n}^{*}$ \\
\hline \multicolumn{7}{|c|}{ Have you smoked cigarettes on school premises/ property? } \\
\hline Yes & 73.0 & $67.2-78.8$ & 162 & 78.7 & $73.4-84.1$ & 177 \\
\hline No & 27.0 & $21.2-32.8$ & 60 & 21.3 & $16.0-26.7$ & 48 \\
\hline Total & 100.0 & & 222 & 100.0 & & 225 \\
\hline \multicolumn{7}{|c|}{ Have you smoked cigarettes in school buildings? } \\
\hline Yes & 12.2 & $7.8-16.6$ & 26 & 22.1 & $16,6-26.6$ & 48 \\
\hline No & 87.8 & $83.4-92.2$ & 187 & 77.9 & $72.4-83.4$ & 169 \\
\hline Total & 100.0 & & 213 & 100.0 & & 217 \\
\hline
\end{tabular}

${ }^{*} n$ is the total number of responses. Differences in the numbers are caused by the missing responses.

cific populations in Turkey, including the medical professionals. It may be the time for medical schools in Turkey to review the GHPSS and GATS findings and decide if tobacco control should be added to their curricula.

\section{SHS Exposure}

Exposure to SHS is detrimental to health and causes many serious diseases $(2,3)$. The GHPSS results indicate that exposure to SHS among medical students is high. Approximately, half (46.9\%) of the medical students reported they had been exposed to tobacco smoke at home, at least one day during the past seven days.

The 2008 GATS study reported that 30.5 million adults (59.7\%) in Turkey were living in homes where smoking was allowed, including 19.5 million non-smokers. The same study showed that over 10 million non-smokers were living in homes, where someone smoked indoors at least daily (9). The 2003 Global Youth Tobacco Survey (GYTS) also showed that $81.6 \%$ of the students in Turkey were exposed to SHS in their homes (13). Boyaci et al. reported that $76 \%$ of the school children included in their study had been exposed to SHS (14).

The percentage of those exposed to SHS was lower in GHPSS than in previous studies. This may be associated with the living environment of the students, since they usually live in a house with their friends or in a dormitory. Lower SHS exposure in GHPSS might also be associated to some extent with the 2008 anti-tobacco law in Turkey. According to recent studies, bans on smoking in public places also decrease smoking at home (15, 16). Nevertheless, almost half of the medical students in GHPSS reported they had been exposed to SHS in their home.

In GHPSS, $42.2 \%$ of the students reported being exposed to SHS in places other than where they live, at least one day during the past seven days. According to a study from Bosnia and Herzegovina, the percentage of medical students exposed to SHS in public places was $94.5 \%$ during the last week (17). In the GHPSS India (2006), 73\% of the students reported having been exposed to SHS in public places (18). The Global Youth Tobacco Survey (GYTS) in the Czech Republic showed that exposure to SHS in public places remained unchanged over time $(74.5 \%$ in $2002,75.2 \%$ in 2007) (19). The 2003 GYTS in Turkey showed that $85.6 \%$ of the students were exposed to SHS in public places (13). In the GYTS $2009,80 \%$ of the Turkish students reported exposure in public places (20). These findings show that there is a slight decrease in exposure to SHS in Turkey.

The findings from GHPSS indicate that although the percentage of students exposed to SHS in public places is still high, it is 
lower than in previous studies - a probable consequence of the enactment of 2008 anti-tobacco law in Turkey. Further studies are needed to assess the impact of the law on SHS exposure.

\section{Attitudes towards Tobacco Use}

GHPSS found that students did support the view that smoking should be banned in all enclosed public places (over $90 \%$ of never smokers and over $70 \%$ of current smokers). Mayda et al. found that $86.1 \%$ of the medical students supported a ban on smoking in enclosed areas (22). Cetinkaya et al. also reported that $90.4 \%$ of the medical students and physicians supported a smoking ban in all public places (23). Similar results were obtained in different countries; e. g. Al-Haqwi et al. reported that $88 \%$ of the medical students in Riyad thought that smoking should be banned in public areas (24). In 2006, over $91 \%$ of students supported a ban on smoking in restaurants and in all enclosed public places in India (18).

The GHPSS findings showed that the majority of medical students supported a ban on the use of tobacco products in enclosed public places. The level of support was higher among never users than current users of tobacco products. Previous literature also shows that non-smokers tend to have a higher support in tobacco related regulations (25).

Official policies of medical schools have a special significance with respect to prevention of smoking and SHS among medical students (26). In this study, $88.2 \%$ of the medical students stated that their schools had an official smoking policy. The percentage of medical schools with an official smoking policy was $50.1 \%$ in Bosnia and Herzegovina (2007); whereas in the India GHPSS, $48.0 \%$ of the students reported that their college had an official smoking policy $(17,18)$.

Enforcement of the existing smoking policies is also crucial for tobacco control and prevention of SHS. Van Huy et al. reported that non-smoking university regulations play a critical role in tobacco control among medical students (10). In this study, 87.2\% of students stated that their school's official smoking ban was enforced. This percentage was reported at $17.4 \%$ in Bosnia and Herzegovina (2007), and 62.9\% in India (2006) $(17,18)$.

In this study, 8 out of 10 current smokers stated that they smoked cigarettes on school premises/property during the past year and 2 out of 10 current smokers smoked inside the medical school buildings. These findings indicate that smoking on medical school property/premises is high despite the ban and school policies. Another factor is that the anti-tobacco law amended in 2008 does not cover outdoor areas of health care facilities. On the other hand, there seems to be a decreasing trend of smoking on medical campuses, since the percentages of students smoking both on school premises/property and inside the medical school buildings were significantly lower in the past 30 days when compared to the past year, indicating an improvement after enactment of the anti-tobacco law. This decrease was greater in the school buildings when compared to the school promises/property. This may be associated with the restriction of the law, which allows smoking outdoors, while it bans smoking in indoor areas of schools. The law allows the teachers and other school staff to smoke in outdoor areas near the schools. The National Tobacco Control Programme and Action Plan of Turkey 2008-2012 includes strategies on integrating and developing curricula for the medical faculties to create changes in knowledge, skills and attitudes on non/smoking (26). Apart from enforcement of the law, implementation of these strategies with respect to education will also contribute to reaching the goal of $100 \%$ smoke-free environments.

\section{Strengths and Limitations}

GHPSS has a standardised methodology for selecting participating schools and classes and uniform data processing procedures. Having a nationally representative sample is another strength of this study. On the other hand, the aforementioned findings can only be generalized for third year medical students in Turkey. Future studies can include health profession students from different faculties, which would give a broader picture of the tobacco problem in different health related disciplines. Another limitation of this study is that it relies on self-reported information. As in similar studies, we cannot rule out a potential social desirability bias, which might especially be important in the case of medical students, as they are expected to act as role models in their communities.

\section{CONCLUSION}

The GHPSS results showed an inconsistency between the 2008 law banning smoking in public places considering the fact that almost 9 in 10 medical schools have policies banning smoking in school buildings and the fact that over 4 in 10 medical students report being exposed to tobacco smoke in public places. Also, smoking on medical school properties, premises, and smoking in school buildings still constitutes a problem.

Results indicate that enforcement of the 2008 anti-tobacco law is needed as well as a careful review of the policies at medical schools. Clearly, exposure to SHS in public places is still high. The 2008 anti-tobacco law and the related smoking policies of medical schools have to be enforced more strongly and actions have to be taken to make necessary legislative changes to cover outdoor areas of health care facilities.

The majority of medical students support tobacco bans, however, high prevalence of smoking among medical students poses a challenge in making medical schools $100 \%$ smoke-free. Since change in the use of tobacco among the general population is linked to changes in behaviour of medical professionals, revision of medical education curriculum has to be implemented to include tobacco control programmes, in order to better respond to tobacco control in Turkey.

\section{Funding}

This work was supported by the World Health Organization Regional Office for Europe (Grant number EU/09/110846)

\section{Acknowledgements}

The authors would like to thank CDC and the WHO Tobacco Free Initiative for their technical assistance in the study design and data analysis as well as the WHO Regional Office for Europe for their financial support.

\section{Conflicts of Interest}

None declared 


\section{REFERENCES}

1. World Health Organization. WHO report on the global tobacco epidemic, 2008: the MPOWER package. Geneva: WHO; 2008.

2. Callinan JE, Clarke A, Doherty K, Kelleher C. Legislative smoking bans for reducing secondhand smoke exposure, smoking prevalence and tobacco consumption. Cochrane Database Syst Rev. $2010 \mathrm{Apr}$ 14;(4):CD005992.

3. U.S. Department of Health and Human Services. The health consequences of involuntary exposure to tobacco smoke: a report of the surgeon general - executive summary. Rockville: U.S. Department of Health and Human Services; 2006.

4. Oberg M, Jaakkola MS, Woodward A, Peruga A, Prüss-Ustün A. Worldwide burden of disease from exposure to second-hand smoke: a retrospective analysis of data from 192 countries. Lancet. 2011 Jan 8;377(9760):139-46.

5. World Health Organization. Protection from exposure to second-hand tobacco smoke: policy recommendations. Geneva: WHO; 2007.

6. Blanke DD, da Costa e Silva V, editors. Tobacco control legislation: an introductory guide. 2 nd ed. Tools for advancing tobacco control in the 21 st century. Geneva: WHO; 2004.

7. European Commission, Directorate General for Health and Consumers Tobacco contol in the EU. FactSheet. Brussels: European Communities; 2009.

8. Sayek I, Kiper N, Odabasi O. Undergraduate medical education report 2008. Ankara: Turkish Medical Association Publications; 2008. (In Turkish.)

9. The Ministry of Health of Turkey, General Directorate of Primary Health Care. Global adult tobacco survey. Turkey report 2010. Ministry of Health publication, no. 803. Ankara: The Ministry of Health of Turkey; 2010.

10. Nguyen VH, Dao TM, Dao NP. Smoking among Vietnamese medical students: prevalence, costs, and predictors. Asia Pac J Public Health. 2008;20(1):16-24.

11. Almerie MQ, Matar HE, Salam M, Morad A, Abdulaal M, Koudsi A, et al. Cigarettes and waterpipe smoking among medical students in Syria: a cross-sectional study. Int J Tuberc Lung Dis. 2008 Sep;12(9):1085-91.

12. Onal AE, Tumerdem Y, Ozel S. Smoking addiction among university students in Istanbul. Addict Biol. 2002 Oct;7(4):397-402.

13. Centers for Disease Control and Prevention. Global Youth Tobacco Survey (GYTS). Country data set: Turkey, 2003. Atlanta: CDC; 2003.

14. Boyaci H, Etiler N, Duman C, Basyigit I, Pala A. Environmental tobacco smoke exposure in school children: parent report and urine cotinine measures. Pediatr Int. 2006 Aug;48(4):382-9.
15. O'Dowd A. Smoking ban in public places also cuts smoking at home. BMJ. 2005 Jul 16;331(7509):129.

16. Roehr B. Bans on public smoking reduce deaths among people exposed to secondhand smoke, study shows. BMJ. 2009 Oct 19;339:b4290.

17. Catak AR. Exposure to environmental tobacco smoke (ets) in dental, medical and pharmacy students in the Federation of Bosnia and Herzegovina. Mater Sociomed. 2007;19(4):190-2.

18. Sinha DN, Singh G, Gupta PC, Pednekar M, Warrn CW, Asma S, et al. Linking India Global Health Professions Student Survey data to the World Health Organization Framework Convention on Tobacco Control. Indian J Cancer. 2010 Jul;47 Suppl 1:30-4.

19. Sovinová H, Csemy L, Warren CW, Lee J, Lea V. Changes in tobacco use among 13-15-year-olds in the Czech Republic - 2002 and 2007. Cent Eur J Public Health. 2008 Dec;16(4):199-204.

20. Erguder T, Polat H, Arpad C, Khoury RN, Warren CW, Lee J, et al. Linking Global Youth Tobacco Survey (GYTS) data to tobacco control policy in Turkey - 2003 and 2009. Cent Eur J Public Health. 2012 Mar;20(1):87-91.

21. Baser S, Hacioglu M, Evyapan F, Özkurt S, Kiter G, Zencir M. The characteristics of smoking habit among adults living in the centre of Denizli. Turkish Thorac J. 2007;8(3):179-84. (In Turkish.)

22. Mayda AS, Tufan N, Bastas S. Attitudes towards smoking and frequency of smoking among students of Duzce Medical School. TAF Prev Med Bull. 2007;6(5):364-70. (In Turkish.)

23. Cetinkaya F, Biricik SS, Nacar M. Prevalance of smoking and attitudes of the physicians and medical students towards smoking. Erciyes Med J. 2006;28(4):163-71. (In Turkish.)

24. Al-Haqwi AI, Tamim H, Asery A. Knowledge, attitude and practice of tobacco smoking by medical students in Riyadh, Saudi Arabia. Ann Thorac Med. 2010 Jul;5(3):145-8.

25. Borland R, Yong HH, Siahpush M, Hyland A, Campbell S, Hastings G., et al. Support for and reported compliance with smoke-free restaurants and bars by smokers in four countries: findings from the International Tobacco Control (ITC) Four Country Survey. Tob Control 2006; 15:iii34iii41.

26. The Ministry of Health of Turkey. National tobacco control programme and action plan of Turkey, 2008-2012. Ankara: The Ministry of Health of Turkey; 2008. 